\title{
Counseling, health services and training of dental in Suka Makmur Binjai
}

\author{
Trimurni Abidin $^{1 *}$, Sondang Pintauli Panggabean ${ }^{2}$, Wandania Farahanny ${ }^{1}$ \\ ${ }^{1}$ Department of Conservative, Faculty of Dentistry, Universitas Sumatera Utara, Medan, \\ Indonesia \\ ${ }^{2}$ Department of Preventive and Public Health Dentistry, Faculty of Dentistry, Universitas \\ Sumatera Utara, Medan, Indonesia \\ *Email: trimurni@usu.ac.id
}

\begin{abstract}
This paper explains the community service activities in Suka Makmur Village, Binjai District, Langkat Regency. The aim is to improve the quality of life of the community through oral health, which is to encourage the emergence of creativity and initiative of each individual or community group in the village of Suka Makmur. Communities actively participate in health programs in their villages, and determine program priorities according to the needs and desires of the community. Overall it can be seen that $95.4 \%$ of the population experienced a low caries experience category, 3.8\% of them had a moderate caries category and there were already $0.9 \%$ of the population who had a high caries risk category.
\end{abstract}

Keywords: Community service, Oral health, Counseling

\begin{abstract}
Abstrak
Makalah ini menjelaskan kegiatan pengabdian kepada masyarakat di Desa Suka Makmur Kecamatan Binjai Kabupaten Langkat. Tujuannya adalah meningkatkan kualitas hidup masyarakat melalui kesehatan gigi dan mulut ini, yaitu mendorong timbulnya kreativitas dan inisiatif setiap individuatau kelompok masyarakat Desa Suka Makmur. Masyarakat ikut secara aktif dalam programprogram kesehatan di desanya, dan menentukan prioritas program sesuai dengan kebutuhan dan keinginan masyarakat. Secara keseluruhan dapat di lihat 95,4\% penduduk mengalami kategori pengalaman karies rendah, 3,8\% di antara nya mengalami karies kategori sedang dan sudah terdapat $0.9 \%$ penduduk yang mengalami kategori resiko karies tinggi.
\end{abstract}

Kata Kunci: Pengabdian Masyarakat, Kesehatan Mulut, Penyuluhan

\section{PENDAhuluan}

\subsection{Latar Belakang}

Pembangunan kesehatan adalah upaya yang dilaksanakan oleh semua komponen bangsa Indonesia yang bertujuan untuk meningkatkan kesadaran, kemauan dan kemampuan hidup sehat bagi setiap orang agar terwujud derajat kesehatan masyarakat yang setinggi-tingginya, sebagai investasi bagi pembangunan sumber daya manusia yang produktif secara sosial dan ekonomis (Kementerian Kesehatan RI, 2015). Derajat kesehatan dipengaruhi oleh beberapa faktor yaitu lingkungan, perilaku, pelayanan kesehatan dan faktor keturunan. Dari keempat faktor tersebut, yang sangat besar pengaruhnya terhadap kesehatan adalah keadaan lingkungan yang tidak memenuhi syarat kesehatan dan perilaku yang masyarakat yang merugikan, baik masyarakat di pedesaan maupun perkotaan. Hal ini disebabkan karena kurangnya pengetahuan dan kemampuan masyarakat di bidang kesehatan, ekonomi maupun teknologi. Hasil interaksi berbagai faktor yang ada, baik factor internal (dari dalam diri manusia), maupun faktor eksternal (dari luar diri manusia), 
yang saling berinteraksi akan tergambar dalam derajat kesehatan masyarakat.

Kesehatan anak dengan rongga mulut yang buruk juga akan berpengaruh terhadap kesejahteraan keluarga, karena orang tua merasa kuatir dan banyak menghabiskan waktu untuk tidak bekerja untuk menemani anak yang sakit giginya dan berusaha menghilangkan sakit gigi dengan mencari perawatan. Selain itu kondisi mulut dan gigi yang tidak sehat dapat mengakibatkan anak kekurangan gizi. Rasa sakit pada gigi dan mulut akan menurunkan selera makan anak dan menyebabkan kemampuan belajar menurun sehingga akan berpengaruh pada prestasi belajar dan anak akan enggan beraktivitas fisik.

Kualitas hidup merupakan istilah umum yang digunakan dalam berbagai disiplin ilmu, seperti politik, ekonomi, agama, termasuk bidang kedokteran. Kualitas hidup adalah suatu nilai yang diberikan dalam durasi kehidupan yang dimodifikasi oleh adanya penyakit, status fungsional, serta kesempatan sosial. Kualitas hidup ini bersifat dinamis dan dipengaruhi oleh penyakit, perawatan,kebijakan kesehatan, serta dimodifikasi oleh kemampuan mengatasi masalah, harapan dan adaptasi masingmasing individu (Allen, 2003). Kesehatan merupakan salah satu komponen kualitas hidup. Kesehatan berkontribusi terhadap kualitas hidup, yang dalam konteks kedokteran adalah mengukur dampak kesakitan (illness), penyakit dan perawatannya terhadap kesejahteraan (welfare) pasien secara lebih mendalam jika dibandingkan dengan hanya menggunakan indicator klinis yang umum digunakan oleh para professional kesehatan (Cunningham dan Hunt, 2001). Seperti yang dinyatakan oleh WHO, sehat adalah sehat menyeluruh secara fisik, mental dan sosial, bukan sekedar bebas dari penyakit dan kelemahan.

\subsection{Rumusan Masalah}

Berdasarkan uraian latar belakang maka permasalahan dalam pengabdian ini adalah sebagai berikut:

1. Dari hasil pengabdian pada masyarakat yang dilakukan oleh residen Program Pendidikan Dokter Gigi Spesialis Koservasi gigi FKG USU dalam Pengabdian Profesor Mengabdi pada tanggal 30 Juli 2019, diperoleh data dari 83 penduduk yang datang untuk memeriksakan giginya, penduduk yang mempunyai karies gigi (D) 157; Gigi hilang (M) 47; Gigi ditambal 3, dengan penduduk yang menderita Pulpitis (P) 15 orang (18\%), mempunyai ulcer (U) di mulutnya 2 orang $(0,02 \%)$ dan yang mempunyai gigi degan fistula (F) 1 orang $(0,01 \%)$.

2. Terlihat perilaku masyarakat yang tidak peduli dengan kesehatannya menimbulkan pertanyaan apakah memang masyarakat Desa Makmur yang tidak mempunyai pengetahuan dan pemahaman tentang hidup sehat, apakah karena letak Puskesmas yang jauh sehingga masyarakat malas untuk memeriksakan kesehatan gigi dan mulutnya, kurangnya penyuluhan mengenai kesehatan gigi dan mulut di Desa Suka Makmur tidak adanya motivator kesehatan gigi dan mulut serta belum adanya program-program kesehatan, khususnya mengenai kesehatan gigi dan mulut.

\subsection{Rumusan Masalah}

Tujuan meningkatkan kualitas hidup masyarakat Desa Suka Makmur Kecamatan Binjai Kabupaten Langkat melalui kesehatan gigi dan mulut ini adalah: Mendorong timbulnya kreativitas dan inisiatif setiap individuatau kelompok masyarakat Desa Suka Makmur, untuk ikut secara aktif dalam programprogram kesehatan di desanya, dan menentukan prioritas program sesuai dengan kebutuhan dan keinginan masyarakat Desa Suka Makmur Kecamatan Binjai. 


\section{METODE PELAKSANAAN}

\subsection{Landasan Teori}

Kecamatan Binjai terletak diantara $03^{\circ} 27^{\prime} 00^{\prime \prime}$ dan $03^{\circ} 42^{\prime} 20^{\prime \prime}$ Lintang Utara serta antara $98^{\circ} 25^{\prime} 20^{\prime \prime}$ dan 98³0'20" Bujur Timur dengan batas-batas wilayah sebagai berikut:

- Sebelah Utara berbatasan dengan Kecamatan Stabat.

- Sebelah timur berbatasan dengan Kabupaten DeliSerdang dan Kota Binjai

- Sebelah Selatan berbatasan dengan Kota Binjai.

- Sebelah Barat berbatasan dengan Kecamatan Selesai.

Luas wilayah Kecamatan Binjai adalah yang terletak lebih kurang 28 meter dari permukaan laut. Secara administrasi Kecamatan Binjai dibagi atas 7 (tujuh ) desa dan 1 (satu) kelurahan.

Luas Kecamatan Binjai adalah 42,05 km2 dengan jumlah penduduk tahun 2017 sebanyak 44.830 jiwa, sehingga rata-rata kepadatan penduduk Kecamatan Binjai sebesar 1.066,11 jiwa/km2, namun pada kenyataannya secara keseluruhan wilayah Kecamatan Binjai mempunyai tingkat kepadatan penduduk yang tidak sama antara satu desa dengan desa yang yang lainnya. Hal ini dapat menimbulkan permasalahan kesehatan jika tidak dilakukan intervensi terutama dalam masalah Kesehatan lingkungan lingkungan.

Perawatan gigi memberikan perubahan yang signifikan terhadap aspek psikologis dan sosial dalam kehidupan anak. Peningkatan ini meliputi berkurangnya rasa sakit dan meningkatnya kemampuan untuk makan dan tidur. Dalam suatu studi, orang tua dengan anak-anak yang mendapatkan perawatan gigi menyatakan bahwa terdapat peningkatan dalam aspek social kehidupan anak-anaknya, yaitu anak terlihat lebih banyak tersenyum, meningkatnya kemampuan di sekolah serta meningkatnya interaksi.

\subsection{Objek Pengabdian}

1. Jajaran pimpinan dan tenaga kesehatan Puskesmas Sambirejo, Kecamatan Binjai, Kabupaten langkat.

2. Pimpinan dan Guru serta siswa SMA Negeri 1 Kecamatan Binjai, Kabupaten Langkat.

3. Pimpinan dan Guru serta siswa SD Negeri Kecamatan Binjai, Kabupaten Langkat.

4. Perangkat Desa dan Masyarakat Umum Desa Suka Makmur, Kecamatan Binjai, Kabupaten Langkat.

\subsection{Metodologi Pengabdian}

Dalam pelaksanaan Desa Binaan ini dilakukan kegiatan antara lain:

1. Melakukan screening kesehatan gigi dan mulut, untuk mendapatkan data-data kesehatan gigi dan mulut masyarakat Desa Sukamakmur.

2. Melakukan pelayanan kesehatan gigi dan mulut bagi masyarakat Desa Sukamakmur.

3. Melatih kader-kader kesehatan gigi dan mulut, untuk membantu tenaga kesehatanyang sudah ada tetapi masih kurang, terutama kader-kader kesehatan gigi dan mulut.

4. Dalam hal ini dilakukan pelatihan kader untuk mendapatkan dokter gigi kecil dari muridmurid

SD. Dengan adanya kader-kader kesehatan gigi dan mulut yang terlatih ini dapat membantu penguatan pelayanan kesehatan primer dalam upaya kesehatan gigi dan mulut murid-murid SD melalui pemberdayaan dokter gigi kecil ini yang dapat menjadi motivator bagi teman-temannya 
untuk meningkatkan kesehatan gigi dan mulutnya. Selain itu akan ada penerapan keberlanjutan pelayanan (Continum of care) dan mendorong terwujudnya gerakan siswa hidup sehat.

\section{HASIL DAN PEMBAHASAN}

\subsection{Penjaringan Kesehatan Gigi dan Mulut (Screening)}

Kegiatan awal pada Desa Binaan Desa Suka Makmur, Kabupaten Langkat dilakukan pada tanggal 7 November 2019 dengan terlebih dahulu mengidentifikasi tingkat kesehatan jaringan mulut masyarakat (DMF-t) masyarakat Desa Binaan melalui program screening (penjaringan) yang dilakukan oleh tim pelaksana dengan membagi Tim menjadi 3 kelompok pada 3 lokasi berbeda yang telah ditentukan bersama sesuai dengan kesepakatan dengan petugas pusat kesehatan setempat yaitu Puskesmas Sambirejo, Kecamatan Binjai, Kabupaten Langkat, Sumatera Utara. Tim tersebut terbagi atas tim yang menjaring kesehatan pada masyarakat umum berlokasi di Puskesmas Pembantu, tim yang menjaring kesehatan pada anak usia remaja dan guru-guru yang berlokasi di SMA Negeri 1 Kecamatan Binjai dan tim yang menjaring kesehatan pada anak usia Sekolah Dasar dan guru-guru yang di pusatkan pada SD Negeri 054871, Kwala Begumit, Kecamatan Binjai, Kabupaten Langkat.
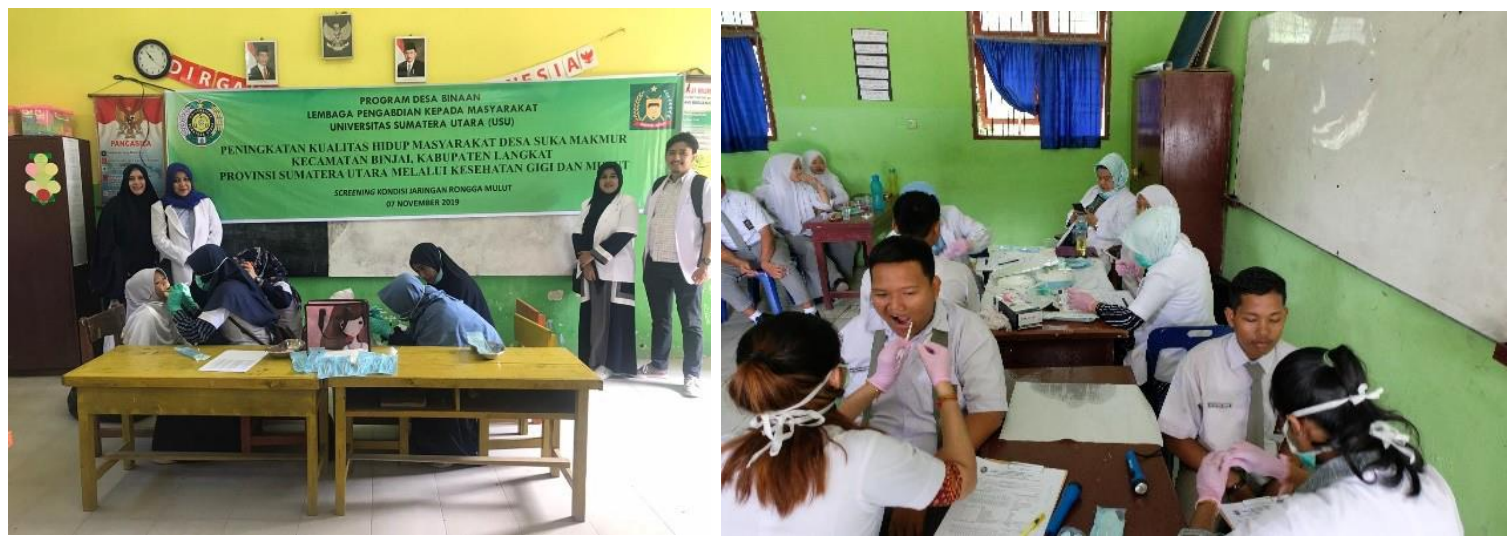

Gambar 3.1 Penjaringan (Screening) kesehatan gigi dan mulut di Desa Binaan Desa Suka Makmur, Kecamatan Binjai, Kabupaten Langkat

Hasil penjaringan (screening), seperti terlihat pada Gambar 3.1, menunjukkan bahwa pada 269 anak usia 6-12 tahun didapatkan indeks karies (D) sebesar 1,6 $\pm 2,08$, indeks kehilangan gigi (M) sebesar 0,04 $\pm 0,28$, serta belum ditemukannya upaya perawatan kesehatan gigi dan mulut pada kelompok usia ini yang ditunjukkan dengan angka 0 pada indeks Filling $(\mathrm{F})$. Total indeks DMF-T sebesar 1,62 $\pm 2,11$ pada anak usia 6-12 tahun. Hasil penjaringan pada 249 anak usia remaja (16-19 tahun) juga memperlihatkan indeks karies (D) sebesar 2,41 $\pm 2,83$; kehilangan gigi (M) sebesar $0,23 \pm 0,82$ dan pengalaman perawatan gigi dan mulut (F) sebesar $0,03 \pm 0,21$ dengan total indeks DMF-T sebesar 2,67 $\pm 2,96$. Hasil penjaringan pada kelompok usia 20-60 tahun menunjukkan pengalaman karies (D) sebesar 5,98 $\pm 4,55$ yang sekaligus juga menunjukkan pengalam karies tertinggi di antara 3 kelompok. Pengalaman kehilangan gigi (M) sebesar 0,23 $\pm 0,82$ dan pengalaman $(F)$ sebesar $0,02 \pm 0,15$. Indeks

DMF-T (42 orang) pada kelompok usia 20-60 tahun sebesar 6,88 $\pm 6,09$ menunjukkan indeks pengalaman karies yang terbesar di antara 3 kelompok di Desa Binaan Desa Suka Makmur, Kecamatan Binjai, Kabupaten Langkat (tabel 3.1). 
Trimurni Abidin et.al. Counseling, health services

Tabel 3.1. Nilai Rerata Pengalaman Karies Berdasarkan Kelompok Usia

\begin{tabular}{cccccc}
\hline Kelompok & $\mathbf{n}$ & $\mathbf{D}$ & $\mathbf{M}$ & $\mathbf{F}$ & $\mathbf{D M F}-\mathbf{T}$ \\
\cline { 2 - 6 } & & $\mathbf{X} \pm$ SD & $\mathbf{X} \pm \mathbf{S D}$ & $\mathbf{X} \pm$ SD & $\mathbf{X} \pm \mathbf{S D}$ \\
\hline $20-60$ & 42 & $5,98 \pm 4,55$ & $0,88 \pm 2,96$ & $0,02 \pm 0,15$ & $6,88 \pm 6,09$ \\
$16-19$ & 249 & $2,41 \pm 2,83$ & $0,23 \pm 0,82$ & $0,03 \pm 0,21$ & $2,67 \pm 2,96$ \\
$6-12$ & 269 & $1,6 \pm 2,08$ & $0,04 \pm 0,28$ & 0 & $1,62 \pm 2,11$ \\
Total & 560 & $2,29 \pm 2,89$ & $0,19 \pm 1,01$ & $0,01 \pm 0,15$ & $2,48 \pm 3,25$ \\
\hline
\end{tabular}

Berdasarkan hasil penjaringan kesehatan gigi dan mulut, maka dapat dikategorikan sebanyak 69\% (29 orang) penduduk usia 20-60 tahun mengalami kategori pengalaman karies rendah, sedangkan $26,2 \%$ (11 orang) dan 4,8\% (2 orang) penduduk dikategorikan dengan pengalaman karies yang sedang dan tinggi secara berurutan. Pada kelompok usia 16-19 tahun, 96\% (239 anak) mengalami karies kategori rendah, 3.2\% (8 orang) kategoripengalaman karies sedang dan $0.8 \%$ (2 orang) di kategorikan memiliki pegalaman karies tinggi. Pada kelompok usia 6-12 tahun, 98,9\% (266 orang) anak sudah terdeteksi dengan pengalaman karies sedang $0.7 \%$ ( 2 orang) dan $0.4 \%$ (1 orang) anak sudah memiliki resiko kategori pengalaman karies tinggi (tabel 4.1.2).

Tabel 3.2. Nilai Kategori Pengalaman Karies Berdasarkan Kelompok Usia

\begin{tabular}{ccccccc}
\hline Kelompok & \multicolumn{2}{c}{ Rendah } & \multicolumn{2}{c}{ Sedang } & \multicolumn{3}{c}{ Tinggi } \\
\cline { 2 - 7 } Usia & $\mathbf{n}$ & $\mathbf{\%}$ & $\mathbf{n}$ & $\mathbf{\%}$ & $\mathbf{n}$ & $\%$ \\
\hline $20-60$ & 29 & 69,0 & 11 & 26,2 & 2 & 4,8 \\
$16-19$ & 239 & 96,0 & 8 & 3,2 & 2 & 0,8 \\
$6-12$ & 266 & 98,9 & 2 & 0,7 & 1 & 0,4 \\
Total & 534 & 95,4 & 21 & 3,8 & 5 & 0,9560 \\
\hline
\end{tabular}

Secara keseluruhan dapat di lihat 95,4\% penduduk mengalami kategori pengalaman karies rendah, 3,8\% di antara nya mengalami karies kategori sedang dan sudah terdapat $0.9 \%$ penduduk yang mengalami kategori resiko karies tinggi.

\section{KESIMPULAN}

Berdasarkan hasil pengabdian kepada masyarakat di Desa Suka Makmur dapat Disimpulkan, bahwa tingginya prevalensi DMF-t dalam masyarakat Desa Suka Makmur terutama pada kelompok usia 20-60 tahun. Tingginya angka kejadian gigi berlubang tidak mendorong masyarakat untuk segera mencari pengobatan ke dokter gigi atau datang ke Puskesmas utama Sambirejo. Hal ini mungkin karena letak Puskesmas Sambirejo yang jauh dari desa dimana dilakukan kegiatan pengabdian sehingga masyarakat belum memahami pentingnya kesehatan gigi dan mulut dalam meningkatkan kualitas hidup. 
Trimurni Abidin et.al. Counseling, health services

\section{UCAPAN TERIMAKASIH}

Penulis mengucapkan terima kasih kepada Rektor dan Ketua LPPM Universitas Sumatera Utara yang telah memberi dana pengabdian kepada masyarakat tahun 2019, melalui Dana NonPNBP Program Desa Binaan.

\section{DAFTAR PUSTAKA}

Allen PF 2003. Review. Assessment of oral Health realted quality of life. Health and quality of life outcome. 1:40. http://www.hqlo.com/content/1/1/40

Cunningham, SJ; hunt, NP.; 2001 Quality of life and its importance in Orthodontics. British Orthodontic Society, JO; Vol 28 (2)

Kemenkes RI. 2015. Peraturan Menteri Kesehatan Republik Indonesia nomor 89 tahun 2015 tentang Upaya Kesehatan Gigi dan Mulut. Jakarta 